\section{Maiden Castle, Dorchester}

EACH succeeding season of Dr. R. E. Mortimer Wheeler's excavation of Maiden Castle adds to the impressive character of the picture of this corner of Britain in prehistoric times which he is reconstructing from the evidence revealed by the spade. The masterly survey of the history of the site from neolithic times, dated approximately at 4,000 B.C., down to the close of Roman domination in the late fourth century of our era, which he gave in his report on the excavations of 1935 to the Society of Antiquaries on February 27, concurs with the evidence of recent excavation elsewhere in showing that life in early Britain, at least in later prehistoric times, was an affair of much more highly organised and settled conditions than has been conceived, even when the story of 'painted' savages is sufficiently discounted. It may be that Dr. Wheeler is right when he sees in the improved and strengthened fortifications, with their elaborated stone-walling reinforcements, which appear at the beginning of the first century B.c., evidence of the driving force of the individual megalomaniac; but the existence even before this of a town of some five to six thousand inhabitants argues no mean standard of culture and considerable ability in ordering and administering the daily details of communal life. In describing the objects which accompanied the remarkable extension of urban fortification and show traces of what is here at Maiden Castle a new culture, Iron Age " $B$ ", Dr. Wheeler suggests that the use of masonry may have come from the west; but it is significant that he does not find that the new culture arrived in any bulk. The population of Maiden Castle appears to him to remain unchanged, but dominated by an administration of an ambitious kind. A further season is to be devoted to the exploration of the site, when one of the principal tasks will be the exploration of the Roman eastern gate and the elaborate prehistoric structures which lie beneath.

\section{Egypt and Asia under the Twelfth Dynasty}

A DISCOVERY of no little importance in its bearing on the relations of Ancient Egypt and Asia under the Middle Kingdom is reported from Toud, the ancient Tuphium, twenty-five miles south of Luxor, where an expedition of the Institut Francais d'Archéologie Orientale is now at work. According to a dispatch from the Cairo correspondent of The Times in the issue of March 2, four small bronze caskets have been found which contain a tribute from Asia to Amenemhet II, one of the Pharaohs of the Twelfth Dynasty who reigned from 2000 to 1790 B.c. They were excavated from sand among the foundations of a temple of Mont, the god of war. The contents of the caskets are lapis lazuli beads and amulets, and ingots of gold, silver and lead. The amulets are said to be of a type hitherto unknown in Egypt. In addition to figures of Asiatic divinities, a human-headed eagle and a winged lion, each of the boxes contained a cylinder with a cuneiform inscription, which has not yet been deciphered.

\section{Imperial Standards}

THE periodical comparison of the Standards of Length and Mass with the Parliamentary copies was due in 1932, and the Board of Trade has just issued a report of 56 pages on the results obtained. The work has been carried out in the Metrology Department of the National Physical Laboratory. As compared with the measurements made in 1922, the four parliamentary copies of the Standard Yard have decreased in length as compared with the Standard itself by 28 millionths of an inch, a change which must be attributed in part at least to an in. crease in length of the Standard Yard. The British copy of the metre has been compared with the Sèvres copies of the Prototype Metre and has been found 0.66 parts in a million short, as compared with 0.60 parts in 1922. Two other copies have retained the lengths they had in 1922. Four Parliamentary copies of the Standard Pound weigh $3 \cdot 6$ and $1 \cdot 1$ thousandths of a grain more, and $0 \cdot 7$ and $3 \cdot 0$ thousandths less than the Standard respectively, the changes since 1922 being slight. The British National copy of the kilogram has been compared with the International Prototype and found to be 58 millionths of a gram too heavy, in good agreement with the 1922 value. The pound has been remeasured as

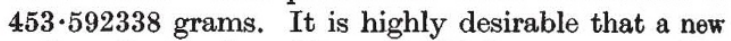
series of pound weights should be constructed of more stable materials than the present standards.

\section{Diesel Engines for Road Transport}

A Comprehensive statement of the present position of the Diesel engine in its application to road vehicles was given by Major Goddard in a paper presented at a joint meeting of the East Midland Section of the Institute of Fuel and the Institution of Mechanical Engineers at University College, Nottingham, on February 20. It is almost eight years since the first Diesel-engined vehicles, two demonstration lorries imported by the Daimler Benz Co., from Germany, were seen in Great Britain and, in the interval, this class of vehicle has been adopted by many transport companies. It is estimated that the number in operation in Great Britain is approximately 12,000 ; more than 900 London buses have already been fitted with Diesel engines, and the rest are being converted as quickly as circumstances permit; the magnitude of the change that is taking place so unobtrusively is probably little realised by the general public. This rapid adoption of the engine in commercial vehicles and, still more, the appearance of a Diesel-engined car-a Bentley with Gardner engine--in the Monte Carlo Rally in 1933, when it gained one of the awards, give a general interest to the information Major Goddard brought together in his paper. After setting out in detail the advantages of this type over the petrol engine, he discussed the conditions under which combustion is controlled and gave figures relative to fuel consumption and economy, speeds and maintenance costs. From these, a clear idea as to current practice and performance can be obtained. In dealing with the advantages of conversion of petrol. engined vehicles to the newer system, given a 